$07.2 ; 09.1 ; 15.2$

\title{
Исследование разупорядочения в твердых растворах теллуридов кадмия-ртути оптическими методами
}

\author{
() В.И. Иванов-Омский ${ }^{1}$, К.Д. Мынбаев ${ }^{1,}$, И.Н. Трапезникова ${ }^{1}$, Д.А. Андрющенко ${ }^{2}$, Н.Л. Баженов ${ }^{1}$, \\ Н.Н. Михайлов ${ }^{3}$, В.С. Варавин ${ }^{3}$, В.Г. Ремесник ${ }^{3}$, С.А. Дворецкий ${ }^{3}$, М.В. Якушев ${ }^{3}$ \\ ${ }^{1}$ Физико-технический институт им. А.Ф. Иоффре РАН, Санкт-Петербург, Россия \\ ${ }^{2}$ Санкт-Петербургский национальный исследовательский университет информационных технологий, механики и оптики \\ (Университет ИТМО), Санкт-Петербург, Россия \\ ${ }^{3}$ Институт ффизики полупроводников им. А.В. Ржанова СО РАН, Новосибирск, Россия \\ `E-mail: mynkad@mail.ioffe.ru
}

Поступило в Редакцию 12 марта 2019г.

В окончательной редакции 12 марта 2019г.

Принято к публикации 13 марта 2019г.

\begin{abstract}
Путем исследования оптического пропускания и фотолюминесценции изучено разупорядочение в пленках твердых растворов теллуридов кадмия-ртути, выращенных с помощью молекулярно-лучевой эпитаксии на подложках из $\mathrm{Si}$ и GaAs. Обсуждаются эффект существенного снижения масштаба разупорядочения в результате термического отжига и возможная связь наблюдаемых явлений с дефектами, типичными для пленок материала, выращенного методом молекулярно-лучевой эпитаксии.
\end{abstract}

Ключевые слова: теллуриды кадмия-ртути, разупорядочение, оптическое пропускание, люминесценция.

DOI: 10.21883/PJTF.2019.11.47819.17782

Твердые растворы (ТР) теллуридов кадмия-ртути (КРТ, химическая формула $\mathrm{Hg}_{1-x} \mathrm{Cd}_{x} \mathrm{Te}$ ) на протяжении многих лет остаются одним из основных материалов для изготовления инфракрасных фотоприемников [1-3]. С момента первых синтезов КРТ в 1958 г. продолжаются дискуссии по поводу возможной степени разупорядочения в этом материале, например о масштабе флуктуаций состава [4-7]. Масштаб разупорядочения может существенно увеличиваться при выращивании КРТ методом молекулярно-лучевой эпитаксии (МЛЭ) [8]. Хотя разупорядочение, как выясняется, не препятствует изготовлению высококачественных фотоприемников [9], важным остается вопрос о его природе, а также о том, насколько его масштаб может быть снижен при постростовой обработке материала. Мы использовали оптические методы для исследования пленок КРТ с близким номинальным (заданным при росте) химическим составом $x$, демонстрировавших после выращивания „обычные“ и „необычные“ свойства, которые могли быть приписаны различной степени разупорядочения ТР, и для отслеживания влияния на эти свойства термического отжига.

Пленки были выращены на подложках (013)Si и (013)GaAs с буферными слоями ZnTe и CdTe в ИФП им. А.В. Ржанова СО РАН по технологии, описанной ранее [10]. Фоточувствительный слой пленок имел однородный по толщине (составлявшей от 5 до $9 \mu \mathrm{m}$ ) состав $x \sim 0.35-0.40$. Свойства пленок исследовались методами оптического пропускания (ОП) и фотолюминесценции (ФЛ). Для этого из выращенных пластин вырезались образцы площадью $\sim 0.3 \mathrm{~cm}^{2}$. Спектры ОП записывались при температуре $300 \mathrm{~K}$ с использованием фурье-спектрометра Shimadzu 8400. Спектры ФЛ записывались при температурах 4.2 и $300 \mathrm{~K}$. Сигнал ФЛ возбуждался полупроводниковым лазером с длиной волны $1.03 \mu \mathrm{m}$ и регистрировался фотодиодом на основе InSb.

Непосредственно после выращивания (as-grown) пленки обладали $n$-типом проводимости с концентрацией электронов при $77 \mathrm{~K}$ по данным исследования эффекта Холла $n=(1-10) \cdot 10^{14} \mathrm{~cm}^{-3}$. Часть образцов была подвергнута постростовому отжигу $\left(260-300^{\circ} \mathrm{C}, 2-6 \mathrm{~h}\right)$ при низком давлении паров ртути $\left(10^{-5} \mathrm{~atm}\right)$ в атмосфере гелия. Такой отжиг обычно используется для перевода образцов из $n$ - в $p$-тип проводимости путем генерации вакансий ртути, акцепторов в КРТ. Часть образцов после этого была подвергнута отжигу для аннигиляции вакансий, приводящему к восстановлению $n$-типа проводимости. Этот отжиг проводился в насыщенных парах ртути при $250^{\circ} \mathrm{C}$ в течение $15 \mathrm{~h}$.

Обычно после выращивания пленки КРТ проходят контроль путем измерения спектров ОП, что позволяет проверить химический состав фоточувствительного слоя и оценить границы спектральной чувствительности будущего фотоприемника [11]. Эта процедура повторяется после термообработки пленки, и на данной стадии резкие изменения формы и положения края спектра ОП могут свидетельствовать о проблемах с однородностью ТР [12]. На рис. 1, a показан пример спектров ОП пленки КРТ, выращенной на подложке из Si. Спектры представлены для as-grown пленки (кривая 1) и образца после отжига для перевода в $p$-тип проводимости (кривая 2). Вид этих спектров является типичным для пленок КРТ, выращенных методом МЛЭ: на спектрах наблюдается резкий край пропускания и выраженные 

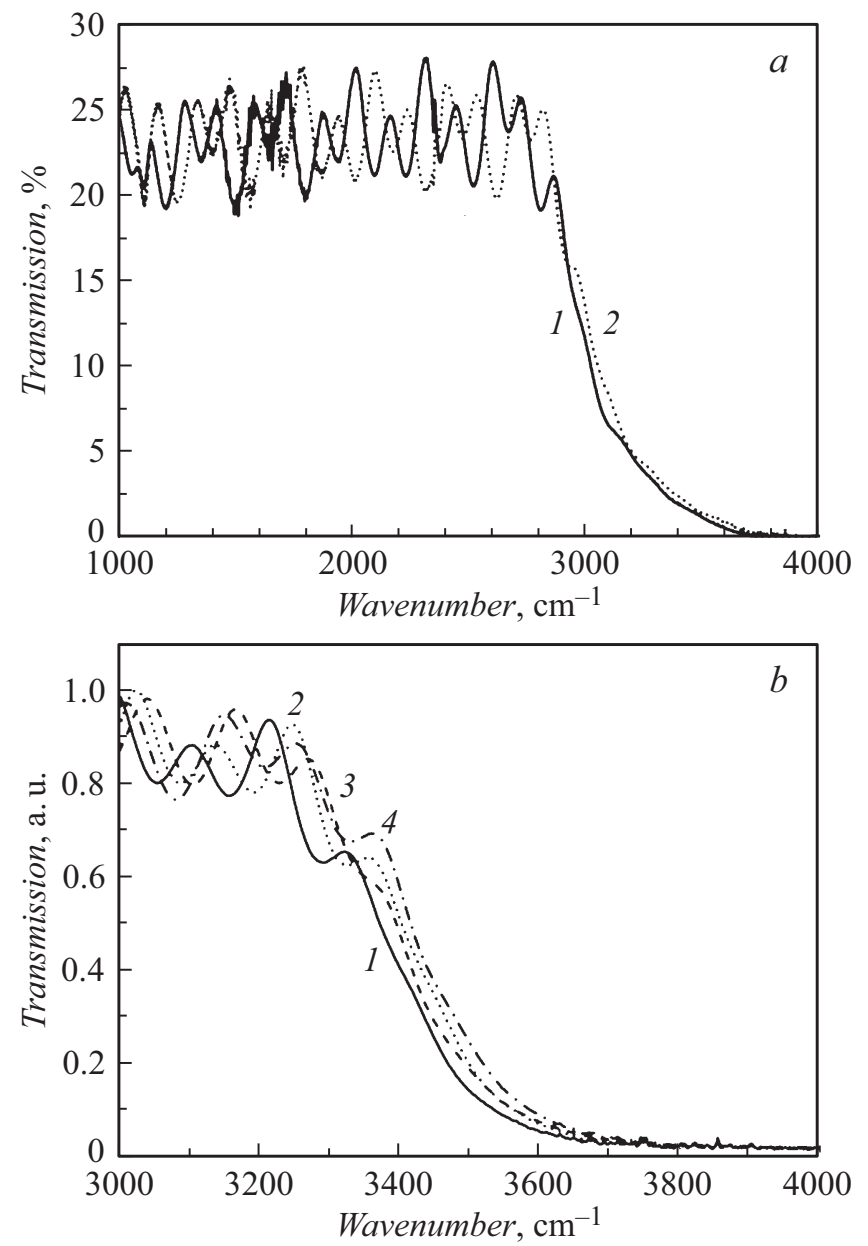

Рис. 1. Оптическое пропускание пленок КРТ, выращенных методом МЛЭ на подложке из Si. $a$ - обзорные спектры as-grown (1) и отожженной (2) пленки с $x=0.346 ; b-$ нормированные спектры материала с $x=0.385$ вблизи края пропускания: as-grown пленка (1), образец после отжига для перевода в $p$-тип проводимости (2), образец после циклического отжига (3) и образец после ионной имплантации и активационного отжига (4).

интерференционные полосы [13]. Из рис. 1, $a$ видно, что отжиг практически не повлиял на вид и положение спектра ОП, а состав пленки после отжига остался прежним $(x=0.346)$. Для данной пленки разброс значений волновых чисел, соответствующих $50 \%$ ОП, по поверхности as-grown пластины диаметром $2^{\prime \prime}$ составил $\pm 3 \mathrm{~cm}^{-1}$, что типично для исследованных образцов.

Рис. 1, $a$ представляет „идеальный“ случай, когда отжиг не привел к сдвигу края ОП. На рис. $1, b$ показаны спектры ОП для другой пленки КРТ, выращенной на подложке из $\mathrm{Si}(x=0.385$ для as-grown пленки). Представлены спектры as-grown материала (кривая 1), пленки после отжига для перевода в $p$-тип проводимости (кривая 2), пленки, подвергнутой циклическому отжигу для уменьшения плотности дислокаций (см. [14]) (кривая 3), и пленки, подвергнутой ионной имплантации с последующим двухстадийным отжигом в насыщенных парах ртути $\left(T=360^{\circ} \mathrm{C}, 2 \mathrm{~h}\right.$ и $T=225^{\circ} \mathrm{C}, 24 \mathrm{~h}$ ) (кривая 4). Различие в значениях волновых чисел, соответствующих $50 \%$ ОП, для кривых 1 и 4 , отстоящих друг от друга на наибольшее расстояние, не превысило $45 \mathrm{~cm}^{-1}$.

На рис. 2, a представлены спектры ОП пленки КРТ с $x=0.376$ (для as-grown материала, кривая 1), выращенной на подложке из GaAs. Для этой пленки после отжига для перевода в $p$-тип проводимости волновое число, соответствующее $50 \%$ ОП, также изменилось незначительно (кривая 2). На рис. 2, $b$ показаны спектры ОП еще одной пленки КРТ, выращенной методом МЛЭ на подложке из GaAs: для as-grown материала (кривая I) и образца после отжига (кривая 2). После отжига здесь наблюдается существенный сдвиг волнового числа, соответствующего $50 \%$ ОП, от 3080 до $3356 \mathrm{~cm}^{-1}$, что для химического состава фоточувствительного слоя означало изменение от $x=0.362$ до $x=0.386$. Следует
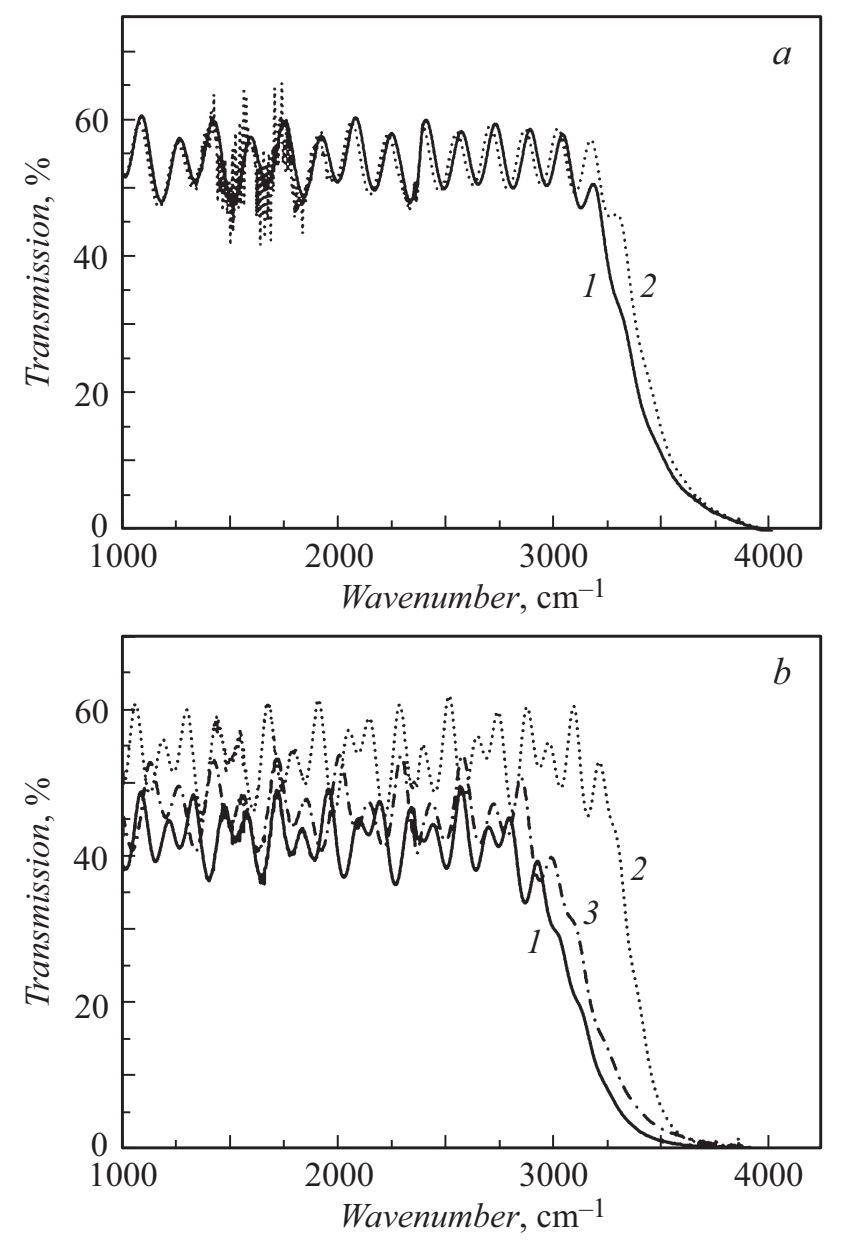

Рис. 2. Спектры оптического пропускания пленок КРТ, выращенных методом МЛЭ на подложке из GaAs. $a$ - as-grown пленка с $x=0.376$ (1) и аналогичная пленка после отжига для перевода в $p$-тип проводимости (2); $b$ - пленка с $x=0.362$, as-grown материал $(1)$, образец после отжига для перевода в $p$-тип проводимости (2) и образец, у которого непосредственно после роста был удален поверхностный слой толщиной $\sim 1.5 \mu \mathrm{m}(3)$. 

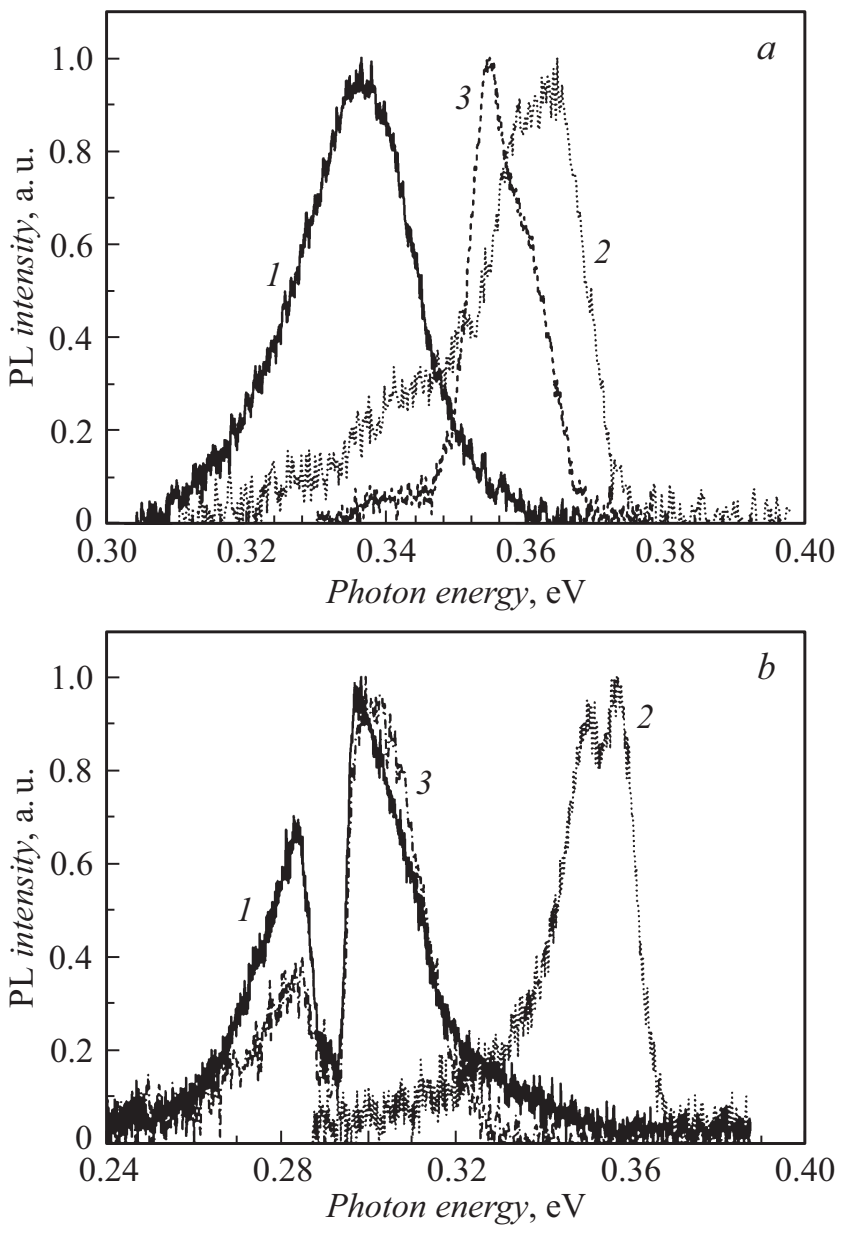

Рис. 3. Нормированные спектры фотолюминесценции пленок КРТ, выращенных методом МЛЭ на подложке из GaAs. $a-$ as-grown пленка с $x=0.376$ (1), образец после отжига для перевода в $p$-тип (2) и образец после отжига для аннигиляции вакансий (3); $b$ - пленка с $x=0.362$, as-grown материал (1), образец после отжига для перевода в $p$-тип проводимости (2) и образец, у которого непосредственно после роста был удален поверхностный слой толщиной $~ 1.5 \mu \mathrm{m}(3)$.

также отметить, что наклон кривой ОП в области края пропускания после отжига стал существенно резче. Для того чтобы убедиться, что в данной пленке отсутствовал градиент состава по толщине, спектр ОП был также записан для образца, у которого после выращивания слой материала толщиной $\sim 1.5 \mu \mathrm{m}$ был удален химическим травлением (кривая 3). Этот спектр оказался очень схожим со спектром, представленным кривой 1 , что подтвердило отсутствие градиента.

На рис. 3, $a$ представлены низкотемпературные $(T=4.2 \mathrm{~K})$ спектры ФЛ обеих пленок, выращенных на подложках из GaAs. Можно отметить различие в энергетическом положении максимумов спектров as-grown пленок (частично объясняемое различными значениями $x)$ и в полуширине спектров. Действительно, для пленки с $x=0.376$ полуширина линии ФЛ (обычно отождествляемой с рекомбинацией экситонов, локализован- ных флуктуациями состава [4-8]) составила $\sim 17 \mathrm{meV}$ (спектр 1 на рис. 3,a), в то время как для пленки с $x=0.362$ полуширина подобной линии была в 2 раза больше - $34 \mathrm{meV}$ (спектр 1 на рис. 3,b). Типичная полуширина данной линии для as-grown пленок КРТ, выращенных методом МЛЭ на подложках из GaAs, при $T=4.2 \mathrm{~K}$, согласно [8], не превышает $20 \mathrm{meV}$. При $300 \mathrm{~K}$ полуширины спектров ФЛ для рассматриваемых as-grown пленок с $x=0.376$ и 0.362 составили соответственно 40 и $50 \mathrm{meV}$. Для первой пленки сдвиг максимума спектра ФЛ при $4.2 \mathrm{~K}$ составил $26 \mathrm{meV}$ после отжига для перевода в $p$-тип проводимости (спектр 2 на рис. $3, a)$ и $18 \mathrm{meV}$ после отжига в насыщенных парах ртути (спектр 3 на рис. 3, a). В результате последнего отжига полуширина спектра ФЛ уменьшилась до $9.3 \mathrm{meV}$. В спектре образца, отожженного для перевода в $p$ тип проводимости, при малых энергиях прослеживается вторая линия, связанная с переходами на акцепторные уровни вакансий.

Для пленки с $x=0.362$ сдвиг максимума спектра ФЛ при $4.2 \mathrm{~K}$ после отжига для перевода в $p$-тип проводимости составил $60 \mathrm{meV}$ (кривая 2 на рис. $3, b$ ). Полуширина экситонной линии ФЛ уменьшилась после этого отжига до $14 \mathrm{meV}$. Таким образом, после отжигов полуширины спектров ФЛ при $4.2 \mathrm{~K}$ для обеих пленок стали близкими. При $300 \mathrm{~K}$ полуширины спектров ФЛ обеих отожженных пленок также были близки и составили $\sim 40 \mathrm{meV}$.

Из приведенных данных следует, что непосредственно после выращивания рассматриваемые пленки обладали существенно различающимися масштабами разупорядочения. Для пленок, выращенных на подложках из $\mathrm{Si}$, и пленки с $x=0.376$, выращенной на подложке из GaAs, этот масштаб был типичным для твердых растворов КРТ, выращенных методом МЛЭ [8]. Для пленки с $x=0.362$, выращенной на подложке из GaAs, этот масштаб был существенно бо́льшим. Аналогичный эффект наблюдался нами и для пленки с $x=0.354$ (as-grown материал), также выращенной на подложке из GaAs. Эксперименты по исследованию ОП этой пленки показали существенное изменение значения волнового числа, соответствующего 50\% ОП, после отжига для перевода в $p$-тип проводимости, в терминах $x$ оно означало увеличение состава до $x=0.382$. При $4.2 \mathrm{~K}$ полуширина экситонной линии ФЛ для as-grown пленки составила $33 \mathrm{meV}$. После отжига для перевода в $p$ тип проводимости полуширина этой линии уменьшилась до $11 \mathrm{meV}$. При $300 \mathrm{~K}$ полуширины линий ФЛ составили $52 \mathrm{meV}$ до отжига и $35 \mathrm{meV}$ после отжига.

Выявленное в работе разупорядочение значительно превышало вызванное флуктуациями химического состава [4-8]. Возможна связь наблюдаемых эффектов с так называемыми „V-дефектами“, присущими материалу, выращенному методом МЛЭ: в областях, примыкающих к $V$-дефектам, наблюдается поликристаллическая фаза [10], которая может претерпевать трансформации при отжигах. С другой стороны, известно, что пленки 
ТР КРТ, выращенные методом МЛЭ, могут обладать слоистой структурой со спонтанной модуляцией состава с периодом в сотни нанометров $[12,15]$. После отжига для таких пленок может наблюдаться сильный сдвиг края ОП, однако в нашем случае он был гораздо меньше, чем тот, о котором сообщалось в [12]. Очевидно, что для установления точной причины выявленного разупорядочения требуются дополнительные исследования. На взгляд авторов, наиболее интересным свойством ТР КРТ, обнаруженным в настоящей работе и требующим дальнейшего изучения, оказывается их способность к существенному упорядочению структуры в результате термического отжига при относительно невысоких температурах.

\section{Конфликт интересов}

Авторы заявляют, что у них нет конфликта интересов.

\section{Список литературы}

[1] Lei W., Antoszewski J., Faraone L. // Appl. Phys. Rev. 2015. V. 2. N 4. P. 041303.

[2] Kinch M. // J. Electron. Mater. 2015. V. 44. N 9. P. 2969-2976.

[3] Rogalski A., Martyniuk P., Kopytko M. // Rep. Prog. Phys. 2016. V. 79. N 4. P. 046501.

[4] Gille P., Herrmann K.H., Puhlmann N., Schenk M., Tomm J.W., Werner L. // J. Cryst. Growth. 1988. V. 86. N 1-4. P. 593-598.

[5] Lusson A., Fuchs F., Marfaing Y. // J. Cryst. Growth. 1990. V. 101. N 1-4. P. 673-677.

[6] Fuchs F., Koidl P. // Semicond. Sci. Technol. 1991. V. 6. N 12C. P. C71-C75.

[7] Oudadjaout D., Marfaing Y. // Phys. Rev. B. 1990. V. 41. N 17. P. $12096-12105$.

[8] Mynbaev K.D., Bazhenov N.L., Dvoretsky S.A., Mikhailov N.N., Varavin V.S., Marin D.V., Yakushev M.V. // J. Electron. Mater. 2018. V. 47. N 8. P. 4731-4736.

[9] Bazovkin V.M., Dvoretsky S.A., Guzev A.A., Kovchavtsev A.P., Marin D.V., Polovinkin V.G., Sabinina I.V., Sidorov G.Yu., Tsarenko A.V., Vasil'ev V.V., Varavin V.S., Yakushev M.V. // Infrared Phys. Technol. 2016. V. 76. P. 72-74.

[10] Sidorov Yu.G., Anciferov A.P., Varavin V.S., Dvoretsky S.A., Mikhailov N.N., Yakushev M.V., Sabinina I.V., Remesnik V.G., Ikusov D.G., Uzhakov I.N., Sidorov G.Yu., Kuzmin V.D., Rihlicky S.V., Shvets V.A., Mardezov A.S., Spesivcev E.V., Gutakovskii A.K., Latyshev A.V. Molecular beam epitaxy of $\mathrm{Cd}_{x} \mathrm{Hg}_{1-x} \mathrm{Te} / /$ Advances in semiconductor nanostructures: growth, characterization, properties and applications. Amsterdam: Elsevier, 2017. Ch. 12. P. 297-323.

[11] Moazzami K., Phillips J., Lee D., Edwall D., Carmody M., Piquette E., Zandian M., Arias J. // J. Electron. Mater. 2004. V. 33. N 6. P. 701-708.

[12] Бахтин П.А., Варавин В.С., Дворецкий С.А., Кравченко А.Ф., Латышев А.В., Михайлов Н.Н., Сабинина И.В., Сидоров Ю.Г., Якушев М.В. // ФТП. 2003. Т. 37. В. 11. C. $1369-1373$.

[13] Yue F., Shao J., Lu X., Huang W., Chu J., Wu J., Lin X., He L. // Appl. Phys. Lett. 2016. V. 89. N 2. P. 021912.
[14] Сидоров Ю.Г., Якушев М.В., Варавин В.С., Колесников А.В., Труханов Е.М., Сабинина И.В., Лошкарев И.Д. // ФTT. 2015. T. 57. В. 11. С. 2095-2101.

[15] Сабинина И.В., Гутаковский А.К., Сидоров Ю.Г., Латышев А.В. // Письма в ЖЭТФ. 2011. Т. 94. В. 4. С. 348-352. 